\title{
Iniciativa para Aumento da Participação Feminina em uma Equipe de Desenvolvimento de Software: um Relato de Experiência
}

\author{
Thiago Meirelles Ventura ${ }^{1}$, Thais Fernanda Bueno da Silva ${ }^{1}$, Daniel Avila \\ Vecchiato $^{1}$, Raphael de Souza Rosa Gomes ${ }^{1}$ \\ ${ }^{1}$ Instituto de Computação - Universidade Federal do Mato Grosso (UFMT) \\ Cuiabá - MT - Brasil \\ \{thiago, daniel, raphael\}@ic.ufmt.br, thaisbueno@ufmt.br
}

\begin{abstract}
There is inequality in the job market in relation to gender, which includes the Information Technology area. Studies show that female participation is lower and, therefore, actions are needed to adjust this scenario. This work reports an experience of detecting a problem involving female students in a selection process, and the actions applied to mitigate the respective problem, from a new selection process to the monitoring of new employees during the execution of their activities. It is hoped that this work will generate attention to similar cases, in addition to suggesting actions to be applied if the scenario is repeated.
\end{abstract}

Resumo. Há desigualdade no mercado de trabalho com relação a gênero, o que inclui a área de Tecnologia da Informação. Estudos mostram que a participação feminina é menor e, portanto, ações são necessárias para ajustar esse cenário. Neste trabalho é relatado uma experiência de detecção de um problema envolvendo discentes do sexo feminino em um processo seletivo, e as ações aplicadas para mitigar o respectivo problema, desde um novo processo seletivo até o acompanhamento das novas colaboradoras durante a execução de suas atividades. Espera-se com este trabalho que seja dada atenção a casos semelhantes, além de sugerir ações a serem aplicadas caso o cenário se repita.

\section{Introdução}

Diversos estudos, como em Borges et al. (2021), Ferreira et al. (2021) e Milson et al. (2021), mostram uma desigualdade no mercado de trabalho entre homens e mulheres nas áreas de Tecnologia da Informação (TI). Inclusive, segundo o estudo da Softex (2019), a mulher perdeu participação no mercado de trabalho de TI entre 2007 e 2017.

Felizmente, ações para tentar resolver esses problemas também são elencadas nos mesmos estudos. Em Sampaio et al. (2020), além de mostrar um histórico da participação feminina na Ciência da Computação, é apresentado projetos que visam promover ainda mais esta participação.

Mesmo com vários projetos ativos para este fim, ainda é possível perceber casos de desigualdade nas organizações e falta de incentivo para o público feminino na área de TI. Uma dessas situações é descrita neste trabalho. 
A experiência relatada neste trabalho ocorreu em uma organização que faz parte de um Instituto de Ensino, e que tem como uma de suas atuações o desenvolvimento de software. Esta organização possui equipe própria e, com o tempo, realiza processos seletivos para contratação de novos colaboradores. Em um dos processos seletivos para estagiários em desenvolvimento de software, nenhuma discente do sexo feminino do mesmo Instituto de Ensino que a organização faz parte se inscreveu, o que não era o esperado. Este trabalho relata os motivos deste cenário, as ações empregadas para tentar reverter a situação e os resultados alcançados.

\section{Detecção do Problema}

Foi iniciado um processo seletivo para ocupar vagas em estágio de desenvolvimento de software. Ao todo eram três vagas, com remuneração de $\mathrm{R} \$ 1.000,00$ e carga horária de 20 horas semanais. A organização em questão tem uma boa avaliação pelos colaboradores e costuma receber várias inscrições em seus processos seletivos. Neste processo seletivo houve a inscrição de 38 candidatos.

Entretanto, apenas três candidatas (8\%) eram do sexo feminino. Destas, nenhuma era do Instituto de Ensino a qual a organização faz parte. Para tentar descobrir o motivo do baixo número de inscritas neste processo seletivo foi feita uma pesquisa com as alunas no respectivo Instituto de Ensino, questionando a principal razão da pessoa não ter se inscrito.

A Figura 1 mostra o resultado da pesquisa. Foram obtidas respostas de 20 alunas, no qual $45 \%$ sinalizaram que não se inscreveram no processo seletivo porque não se sentiram capacitadas para concorrer à vaga.

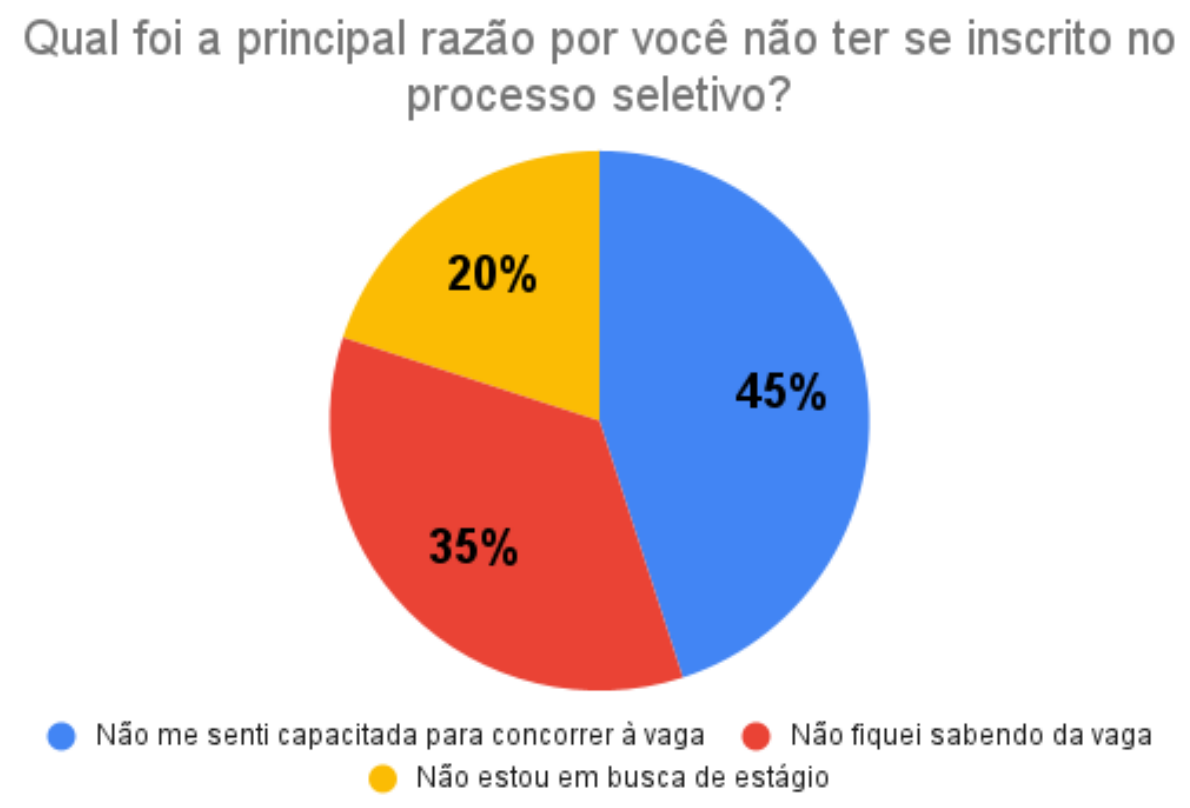

Figura 1. Gráfico mostrando a distribuição de respostas comentando a razão da discente não ter se inscrito no processo seletivo. 
Na mesma pesquisa havia um campo aberto para comentários gerais. Um dos comentários deixados especificava que a aluna já fora subestimada por colegas e que geralmente não se candidatava às vagas por achar que não atendia ao menos um dos requisitos listados.

Ao saber deste cenário, ações foram planejadas para auxiliar as alunas em busca de estágio em áreas relacionadas a desenvolvimento de software.

\section{Ações para Mitigar o Problema}

De acordo com a detecção do problema citado na seção anterior, foi planejado o lançamento de um novo processo seletivo, com o objetivo de contribuir com a formação de alunas e valorização como estudante de tecnologia da informação, pois são minoria, bem como promover a diversidade na equipe do projeto em questão.

A ideia do novo processo seletivo não teve resistência da equipe atual e possuía as seguintes características:

- exclusivo para discentes do sexo feminino;

- diminuição da lista de requisitos para evitar desistências mesmo antes da inscrição no processo seletivo;

- ampliação das áreas de atuação, esclarecendo que seria analisado o perfil da candidata para posteriormente definir a atividade principal de atuação;

- mesmo valor da bolsa e carga horária em relação ao processo seletivo anterior.

No edital de ampla concorrência, houve 38 inscrições para 3 vagas. O processo seletivo para mulheres teve número de inscritos semelhantes (35 candidatas), mas para apenas 1 vaga, incluindo estudantes de outros municípios. Portanto, pode ser considerado que o processo seletivo com ação afirmativa obteve um bom número de inscrições, uma vez que a concorrência foi de 12,67 para 35 por vaga, além da consideração sobre a limitação de ser apenas para o público feminino.

Após as fases do processo seletivo, a equipe do projeto decidiu contratar não apenas uma, mas quatro candidatas, sendo duas para área de desenvolvimento de software e duas para análise de sistemas. Os objetivos dessas contratações eram de prepará-las para o mercado de trabalho e ampliar a representatividade feminina na equipe, incentivando outras a participarem dos próximos processos seletivos.

\section{Resultado das Ações}

No estudo feito por Microsoft (2017) foram elencados cinco fatores para incentivar mulheres nas áreas de ciência, tecnologia, engenharia e matemática, sendo eles: modelos femininos a quem possam se identificar; experiências práticas; mentoria; aplicabilidade na vida real; confiança que serão tratadas com igualdade. Seguindo esta ideia, as ações realizadas aumentaram o número de mulheres na equipe, o qual pode incentivar outras alunas a participarem nos próximos processos seletivos.

O estágio proporcionou experiências práticas, inclusive em uma aplicação sendo utilizada em todo o Estado de Mato Grosso. As duas estagiárias da área de análise de sistemas tiveram a oportunidade de trabalhar com o framework Scrum, com quadro Kanban, elicitação de requisitos, prototipação, escrita de documentação de software 
como, por exemplo, documento de requisitos, especificação de caso de uso, diagrama de caso de uso e modelagem de diagramas de entidade-relacionamento. As demais estagiárias de desenvolvimento de software trabalharam com o framework .NET core, arquitetura MVVM (do Inglês, Model-View-ViewModel), C\#, git, Entity Framework, banco de dados SQL Server e ETL (do Inglês, Extract, Transform, Load).

Foram realizadas mentorias com as novas estagiárias com acompanhamento diário, desde o processo seletivo até o fim do estágio. $\mathrm{O}$ foco foi na aprendizagem da metodologia de desenvolvimento e das tecnologias utilizadas no projeto para o qual foram alocadas. Além disso, ao fim do período de estágio, conversas e incentivo para inscrição em novas posições foram feitas para que elas pudessem prosseguir com os seus aprendizados em outra organização.

Em pesquisa realizada com as estagiárias selecionadas neste processo seletivo, apenas uma das participantes afirmou não ter se inscrito na vaga por se tratar exclusivamente de um processo seletivo de ação afirmativa, porém $100 \%$ acreditam que esse tipo de iniciativa deveria ocorrer novamente.

Sobre o desenvolvimento profissional das estudantes, a equipe de gestão do projeto conseguiu verificar considerável melhoria de soft skills, como comunicação com a equipe, no decorrer do período de estágio. Esta avaliação usou como base a entrevista durante o processo seletivo, onde foram avaliadas a capacidade de comunicação, além da observação no desenvolvimento das participantes durante o período de estágio. A percepção de melhoria em habilidades interpessoais também foi constatada pelas próprias estudantes, que afirmaram em uma pesquisa pós-estágio que o período no projeto contribuiu para o desenvolvimento de habilidades como a comunicação com os colegas de equipe.

Em relação ao conhecimento técnico, as participantes afirmaram que se sentem mais preparadas tecnicamente para novos desafios profissionais, no qual a maioria afirmou se sentir mais motivada a participar de novos processos seletivos de estágio/emprego. Em relato, uma das participantes afirma que ter participado do projeto como estagiária foi uma experiência enriquecedora para conhecimentos técnicos e que a ajudou a desenvolver confiança para procurar novas colocações no mercado de trabalho. Sendo um dos objetivos deste processo seletivo auxiliar no crescimento da auto-estima profissional das estudantes, este é considerado um resultado positivo.

Atualmente, após finalização do período do estágio, as participantes estão trabalhando na área de tecnologia da informação e/ou participando de algum processo seletivo para colocação no mercado de trabalho. Este resultado é considerado muito satisfatório, pois houveram esforços por parte da equipe do projeto em incentivar a participação em processos seletivos para que houvesse a continuidade do desenvolvimento profissional das participantes.

O único feedback negativo recebido pela equipe do projeto foi a dificuldade em pedir ajuda de colegas da equipe técnica. Apesar do projeto usar de metodologia ágil que incentiva a comunicação entre equipe e o apoio entre os membros do time, as participantes ainda não se sentiam totalmente confiantes para pedir ajuda. Para experiências futuras, maior atenção com relação a este feedback será dada para melhor experiência das participantes no projeto. 
Esta foi a primeira experiência em um processo seletivo para contratação de estagiárias na organização. Apesar dos feedbacks positivos, outras questões podem ser consideradas em novas ações futuras. Por se tratar de uma organização dentro de um ambiente universitário, ações como palestras, workshops, mentorias podem ser realizadas visando atingir o objetivo de auxiliar as estudantes no seu desenvolvimento profissional e acadêmico, sabendo das dificuldades enfrentadas no mercado devido ao preconceito de gênero. Estas ações serão planejadas como trabalhos futuros.

\section{Considerações Finais}

Baseado em um cenário problemático detectado em um processo seletivo, buscou-se ações para mitigar o problema da baixa participação feminina em uma equipe de desenvolvimento de software. O principal motivo da baixa participação, segundo as próprias discentes, está relacionado ao sentimento de não ter capacidade de concorrer à vaga. Assim, foi feito um novo processo seletivo, desta vez com características específicas para que as discentes do sexo feminino se sentissem mais capazes de participar.

Quatro estagiárias foram contratadas por meio do novo processo seletivo. Após o período do estágio, foi possível constatar que a experiência ajudou-as a desenvolver habilidades interpessoais, as preparou tecnicamente para novos desafios profissionais, motivou-as a participarem de novos processos seletivos e aumentou a possibilidade de continuar atuando na área de tecnologia da informação.

Por outro lado, a amostra de dados deste trabalho é pequena, uma vez que foram acompanhadas apenas quatro estagiárias. E este relato de experiência e suas respectivas interpretações foram baseadas em situações observadas durante o período de contratação e execução do estágio, além da utilização de entrevistas após o encerramento do estágio. Desta forma, é aconselhado estudos futuros com uma amostra maior, acompanhando diferentes tipos de ações e perfis, a fim de disponibilizar mais dados e discussões sobre o tema.

Por fim, além do impacto positivo para as quatro alunas selecionadas, espera-se com estas ações que outras discentes do sexo feminino se sintam confiantes em concorrer às próximas vagas a serem oferecidas, tanto nesta organização quanto em outras.

\section{Referências}

Borges, A., Sousa, F., Holanda, M., Araujo, A. P. F., Koike, C. C., Oliveira, R. B. (2021). Participação Feminina na Empresa Júnior de Computação - CJR da Universidade de Brasília. In Women in Information Technology (WIT), 161-169. Sociedade Brasileira de Computação. DOI: https://doi.org/10.5753/wit.2021.15852.

Ferreira, P. N., Almeida, L. D., Siqueira, A. S., Pereira, B. (2021). Relato de Experiência: Comunidade de Inteligência Artificial para Mulheres. In Women in Information Technology (WIT), 170-179. Sociedade Brasileira de Computação. DOI: https://doi.org/10.5753/wit.2021.15853.

Microsoft, (2017). Why Europe's girls aren’t studying STEM. Microsoft Philanthropies. 
Milson, A. L. S., Laboissiere, L. M., Ferreira, M. D., Cardoso, R., Brandão, M. A. (2021). Relato de Projeto para Disseminação e Apoio à Participação de Mulheres em Áreas da Ciência. In Women in Information Technology (WIT), 350-354. Sociedade Brasileira de Computação. DOI: https://doi.org/10.5753/wit.2021.15880.

Sampaio, C. M., Venturini, M. A. D., Vanessa, A. B. (2020). Incentivos à participação feminina na área da Ciência da Computação. Revista Alomorfia, v. 4, n. 2, 67-85.

Softex, (2019). Mulheres na TI: atuação da mulher no mercado de trabalho formal brasileiro em tecnologia da informação. Ministério da Ciência, Tecnologia, Inovações e Comunicações (MCTIC). 